\title{
O FOCO TRIPLO: UMA ABORDAGEM PARA A EDUCAÇÃO, DE DANIEL Goleman; Peter Senge. TraduÇão Cássio Arantes leite, RIO DE JANEIRO: OBJETIVA, 2015. 128 P.
}

\begin{abstract}
Adriano Augusto Fidalgo
Bacharel em Ciências Jurídicas e especialista em Processo Civil pela Universidade São Francisco. Especialista em Direito Tributário pela Escola Superior de Advocacia (ESA), da OAB/SP. Especialista em Computação Forense pela Universidade Mackenzie. Master of Business Administration (MBA) em Auditoria e mestre em Educação pela Universidade Nove de Julho. fidalgo@aasp.org.br
\end{abstract}

\section{Para citar - ABNT NBR 6023:2018}

FIDALGO, Adriano Augusto. Resenha. Cadernos de Pós-graduação, São Paulo, v. 19, n. 2, p. 266-269, jul./dez. 2020. Resenha da obra de GOLEMAN, Daniel; SENGE, Peter. O foco triplo: uma abordagem para a educação. Tradução Cássio Arantes Leite. Rio de Janeiro: Objetiva, 2015. 128 p. Disponível em: https://doi.org/10.5585/cpg.v19n2.8868.

Daniel Goleman, ph.D. Psicólogo formado pela Universidade Harvard, durante doze anos escreveu para o New York Time. Autor também das seguintes obras: Trabalhando com a inteligência emocional (1999), O cérebro e a inteligência emocional (2012), Foco (2014) e liderança (2015).

Peter Senge, ph.D., é professor no Massachusetts Institute of Technology, fundador da Society for Organizational Learning (SOL) e autor de A quinta disciplina: Arte e prática da organização que aprende (1990).

O livro é dividido em cinco partes, como será destacado a seguir.

Parte um. Relembrou Goleman que, quando estava escrevendo o livro de inteligência emocional conheceu um dos primeiros currículos voltados para fomentar a inteligência emocional nas escolas de New Haven, Connecticut, porque um psicólogo de Yale deu ouvidos ao prefeito da cidade, por onde um ciclo de mães solteiras ia se sucedendo, bem como, em razão dos modelos de sucesso locais serem os traficantes.

Prosseguiu Goleman que, assim, Roger Weissberg, desenvolveu um dos programas pioneiros de "Aprendizagem Social e Emocional" (ASE). Notou-se que os alunos envolvidos em tais programas tiveram resultados mais satisfatórios, conforme estatísticas, prestando mais atenção, pois aprenderam a controlá-la de forma mais eficaz.

Enfatizou o autor (Goleman) que acompanhou um estudo da W. T. Grant Foundation, por onde eles estavam interessados em diversos problemas dos jovens, como guerras envolvendo as 
drogas, a violência, a pobreza, o bullying, de modo que, todos os programas destinados a ajudar os alunos não funcionavam.

Alguns foram prejudiciais. Mas os que ajudaram tinham determinados ingredientes ativos em comum. Os ingredientes ativos se referiam a competências emocionais e sociais, tais como, autoconsciência, autogestão, empatia, habilidades sociais, para relacionamentos harmoniosos e recorrem a "conjuntos de habilidades em inteligência emocional para você tomar decisões acertadas na vida” (p. 18).

São competências centrais da ASE os seguintes cinco pontos: autoconsciência, autogestão, empatia, habilidade social e boa capacidade de tomada de decisões.

Parte 2. Goleman também relatou uma experiência de alunos do segundo ano de uma escola primária de New Haven, em uma aula de alfabetização emocional, ou seja, uma lição de autoconsciência, em que se observou a importância de se administrar emoções. A autoconsciência dirigindo os pensamentos e sentimentos ajuda a gerir a nossa consciência para dentro e monitorar o caminho do nosso foco.

O cérebro está em evolução até os vinte e poucos anos de idade de uma pessoa, alimentado por suas experiências. Frisou-se que, conforme pesquisas, o nosso cérebro divaga cerca de $50 \%$. Deve-se trabalhar a aprendizagem social e emocional, inclusive para ajudar a perceber o que a outra pessoa está sentindo. Já os comandos cerebrais contra emoções fortes, perturbadoras como raiva ou ansiedade costumam a crescer com a idade, embora fiquem defasados na adolescência.

Parte 3. Destaca Goleman que há estudos que mostram que crianças em risco alcançaram o sucesso, pois tiveram um adulto afetuoso, por vezes um professor. Releva que os administradores precisam dar uma base segura para que os professores atinjam tal desiderato. Quanto mais preocupados, mais focamos em nós mesmos. Há programas que visam dar à criança o antídoto a uma visão unidimensional. Em suma, sobressai a importância da compaixão e da empatia.

Os dispositivos eletrônicos são ambientes particularmente arriscados. Sem as reações presenciais, as emoções humanas ficam em segundo plano. $O$ fenômeno cyber-desinibição deixa as emoções sem controle, aniquiladas pelos freios presenciais. Apontou que um paradoxo entre a tecnologia e o uso da ASE é o afastamento do contato social, aproximando os indivíduos das telas e afastando das pessoas, além de afastá-las da vida real.

Daí, a importância que a ASE dá à participação de pais, professores e colegas de estudo, com suas interações humanas. Contudo, Peter Senge destaca que a tecnologia pode ser importante nesse processo, com a reinvenção do conceito de educação básica, no exercício do pensamento sistêmico, além de ajudar os alunos em três tipos de foco: autoconsciência, foco nos outros e compreensão de sistemas mais amplos e de como eles se aplicam a nossas vidas. 
Tratou Senge sobre a visão sistêmica e a implementação efetiva, justificando que os professores precisam desenvolver novas habilidades, com treinamentos, de modo a alinhar professores e administradores em tal problema sistêmico. Exemplifica com os sistemas biológicos e sociais, a serem tidos como uma dimensão animadora, com o intento de ser relevante no processo educacional.

Parte 4. Destaca Senge que a interdependência e a interconectividade sempre esteve presente. Nossa inteligência sistêmica inata deve ser cultivada. Essa compreensão dos sistemas da natureza semearam os alicerces para compreendermos os sistemas sociais. Duas décadas de pesquisa aplicada à prática educacional revelaram a robustez e a profundidade dessa inteligência sistêmica nativa.

Hoje, escolas têm usado ferramentas e pedagogia inovadora para aplicação da inteligência sistêmica, gerando nos alunos a sensação de eficiência para enfrentar a multiplicidade de desafios sociais e ambientais. Deu-se como exemplos da complexidade dinâmica o uso do giroscópio e andar de bicicleta. Também exemplificou a questão dos delays, isto é, quando obscurecem a nossa compreensão de um assunto pretérito que tem consequências no momento atual.

Senge, como observador e ajudante dos mestres educadores, exaltou a importância sobre a inteligência sistêmica inata dos alunos. De maneira que ela deve ser provocada pelas devidas ferramentas. A separação de matérias e assuntos desconexos pode atrapalhar a inteligência sistêmica. O que os educadores combatem com ferramentas básicas, tais como, os "13 Hábitos de um Pensador Sistêmico".

Explicitou como os Hábitos de um Pensador Sistêmico estão difundidos e são utilizados pelos educadores, notando-se que vale cultivar a inteligência sistêmica e que ela traz aos educadores e alunos uma forte sensação de eficácia, conforme relatos. Enfim, está em jogo a nossa eficiência coletiva, dados os desafios sociais que a espécie humana enfrenta. Não somos a espécie mais rápida ou a mais forte; o que nos distinguiu até os dias atuais é o nosso poder de construir coisas juntos e construir uma comunidade. A educação sistêmica é importantíssima para nós todos como sociedade, por todos esses argumentos.

Parte 5. Os autores, Goleman e Senge, analisaram a questão da teoria ocidental da fragmentação do pensamento, o que causa um resultado reducionista. Com a visão do universo interdependente se acolhe tanto a síntese como a análise, corporificando a inteligência sistêmica, no tempo. Citam que, com o estudo de tais situações, os adolescentes ganham mais complexidade dinâmica, tornando a compreensão cada vez mais sofisticada da complexidade social.

Prosseguem os autores destacando que é importante o desenvolvimento de competências cognitivas, emocionais e sociais, com o fito de despertar a sensibilidade do alunado. Destaca-se que 
a integração cognitiva, emocional, espiritual e energética pode extrair o genuíno potencial dos alunos, ou seja, priorizando a síntese em detrimento da análise. Refletem sobre o modelo que temos desde a Revolução Industrial e que nada acrescenta.

Com as lentes da ASE e do trabalho sistêmico há a possibilidade de uma inovação qualitativa fundamental. Colocou-se em destaque a importância de se educar as famílias. Relacionando a visão fragmentada entre teoria e prática, com a relevância de tornar a educação mais significativa, envolvente e profunda para todos os alunos. A mudança sistêmica requer um esforço do professor moldado em modelos antigos. Devem ser construídas ecologias de liderança, com o envolvimento dos líderes do processo de construção, com a participação de professores e administradores.

Como visto, o livro aborda interessantes exemplos de como a aprendizagem social, emocional e sistêmica têm relevância nos momentos atuais, dada a dinâmica das ferramentas tecnológicas, dada as novas abordagens que saltam da sociedade da informação, bem como, pela velocidade que a informação é repassada aos discentes.

Destaca-se que, para esse novo nível de aprendizagem, deve haver um envolvimento social, com a contribuição dos pais, alunos, professores, escola e sociedade, com o mister de fazer com que o entendimento próprio, do outro, do meio e dessa interligação sistêmica, vendo os alunos o todo, otimizem sobremaneira o aprendizado, com melhores resultados.

Com tal instrumental do ASE, atingir-se-ão algumas habilidades essenciais, para que se consiga a autoconsciência, a empatia e o entendimento de nossas relações com o mundo. Ganhando os discentes o devido rendimento no desempenho acadêmico, o desenvolvimento pessoal e nos relacionamentos, conforme defendem os autores.

Nota-se que a obra tem alguma proximidade com a Pedagogia da Autonomia de Paulo Freire. E o trabalho sistêmico tem muitas características que se interligam com o Pensamento Complexo de Edgar Morin. A temática da obra é interessante para aplicar no modelo brasileiro, mas com as ressalvas das particularidades de nosso sistema de ensino atual, considerando as limitações de equipamentos das escolas públicas e a falta de valorização dos docentes da rede pública, pelo Estado Brasileiro.

Assim, a sua leitura é recomendada para quem atua na área de educação aliada com instrumentos tecnológicos, apontando a referida obra, com exemplos práticos e teóricos, como sanar as demandas das novas gerações e do mundo contemporâneo, com ferramentas que são: a autoconsciência, a empatia e o entendimento de nossa relação com o mundo. Temas de atualidade complexa. 